\title{
Correction: The effect of executive walk rounds on nurse safety climate attitudes: A randomized trial of clinical units
} [ISRCTN85 | 47255]

\author{
Eric J Thomas*1, J Bryan Sexton², Torsten B Neilands ${ }^{3}$, Allan Frankel ${ }^{4}$ and \\ Robert L Helmreich ${ }^{5}$
}

\begin{abstract}
Address: ${ }^{1}$ Department of Internal Medicine, The University of Texas Medical School at Houston, Houston, TX, USA, ${ }^{2}$ Department of Anesthesiology and Critical Care Medicine, Johns Hopkins Quality and Safety Research Group, The Johns Hopkins University School of Medicine, Baltimore, USA, ${ }^{3}$ Center for AIDS Prevention Studies (CAPS), University of California, San Francisco, San Francisco, CA, USA, ${ }^{4}$ Partners Healthcare System, Prudential Tower, Boston, MA, USA and ${ }^{5}$ Department of Psychology, The University of Texas at Austin, Austin, TX, USA

Email: Eric J Thomas* - eric.thomas@uth.tmc.edu; J Bryan Sexton - jsexton2@jhmi.edu; Torsten B Neilands - TNeilands@psg.ucsf.edu;

Allan Frankel - afrankel@partners.org; Robert L Helmreich - helmreich@psy.utexas.edu

* Corresponding author
\end{abstract}

Published: 10 June 2005

BMC Health Services Research 2005, 5:46 doi:10.1 186/1472-6963-5-46

This article is available from: http://www.biomedcentral.com/I472-6963/5/46

(C) 2005 Thomas et al; licensee BioMed Central Ltd.

This is an Open Access article distributed under the terms of the Creative Commons Attribution License (http://creativecommons.org/licenses/by/2.0), which permits unrestricted use, distribution, and reproduction in any medium, provided the original work is properly cited.
Received: 09 June 2005

Accepted: 10 June 2005
Following publication of this article [1], the study was included in the International Standard Randomised Controlled Trial Number (ISRCTN) Register and assigned the number ISRCTN85147255.

\section{References}

I. Thomas EJ, Sexton JB, Neilands TB, Frankel A, Helmreich RL: The effect of executive walk rounds on nurse safety climate attitudes: A randomized trial of clinical units. BMC Health Services Research 2005, 5:28.

\section{Pre-publication history}

The pre-publication history for this paper can be accessed here:

http://www.biomedcentral.com/1472-6963/5/46/prepub 